$1-1-1974$

\title{
Engineering analysis of grafted apple trees as related to fruit supporting capacity
}

\author{
R. H. Fockel
}

Follow this and additional works at: https://researchrepository.wvu.edu/ wv_agricultural_and_forestry_experiment_station_bulletins

\section{Digital Commons Citation}

Fockel, R. H., "Engineering analysis of grafted apple trees as related to fruit supporting capacity" (1974). West Virginia Agricultural and Forestry Experiment Station Bulletins. 635T.

https://researchrepository.wvu.edu/wv_agricultural_and_forestry_experiment_station_bulletins/714 @ WVU. It has been accepted for inclusion in West Virginia Agricultural and Forestry Experiment Station Bulletins by an authorized administrator of The Research Repository @ WVU. For more information, please contact ian.harmon@mail.wvu.edu. 


\section{Engineering Analysis of \\ Grafted Apple Trees \\ As Related to \\ Fruit Supporting Capacity}

\section{Bulletin 635T}

December 1974

West Virginia University

Agricultural Experiment Station

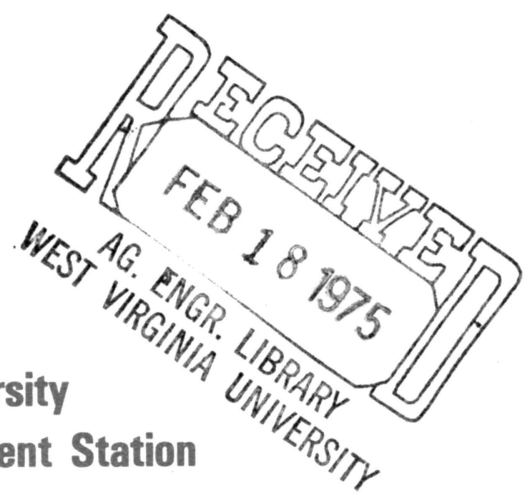




\title{
THE AUTHORS
}

R. H. Fockel was a Graduate Assistant, Agricultural Engineering, at the time of this study; R. G. Diener is Associate Agricultural Engineer; J. P. Kuehn is Associate Agricultural Economist; and R. E. Adams is Plant Pathologist.

\section{ACKNOWLEDGMENT}

The National Science Foundation provided part of the funding for this study under Grant GK-1175.

\author{
West Virginia University \\ Agricultural Experiment Station \\ College of Agriculture and Forestry \\ Homer C. Evans, Acting Direcor \\ Morgantown
}




\title{
Engineering Analysis of Grafted Apple Trees as Related to Fruit Supporting Capacity
}

\author{
R. H. Fockel, R. G. Diener, J. P. Kuehn, and R. E. Adams
}

\section{The Importance of Apple Production in West Virginia}

In 1971, West Virginia ranked seventh in the nation in apple production with 275 million pounds (1972 Agricultural Statistics). Cash receipts from farm marketing of apples amounted to $\$ 10,812,000$ in 1968 , which accounted for 43.5 per cent of all crops and 10.8 per cent of all agricultural commodities marketed in the State (1969 West Virginia Agricultural Statistics).

The production of West Virginia apples took place on 201 commercial apple orchards in 1967. There were 877,780 trees planted on 19,100 acres (1969 West Virginia Agricultural Statistics). Eighty-nine per cent of the trees were standard apple trees and 11 per cent were grafted dwarf and semi-dwarf varieties (1967 Regional Summary of Fruit Tree Surveys, USDA, SRS).

\section{Grafting}

Grafting is the process of asexual propagation of shoots or buds of one plant or tree on the stem or trunk of another, where it continues to grow, becoming a permanent part. The upper part of the tree is termed the scion while the lower part is called the rootstock or understock.

The techniques of grafting have permitted the development of dwarf and semi-dwarf trees. These new types of trees have been gaining in importance (Figure 1) since their development. They have several advantages over the larger standard varieties which account for the increase in their use in new orchards.

\section{Advantages of Grafted Apple Trees}

The height of dwarf trees is often only one third to one half the size of standard trees. However, more dwarf or semi-dwarf trees can be planted per acre, allowing higher productivity per acre than that of standard sized orchards. Furthermore, dwarfed trees can start bearing up to four years sooner than standard types depending on variety, rootstock, and management.

Fruit on dwarfed trees is generally larger and the color superior to standard tree fruit because a larger proportion of the fruit bearing area is exposed to sunlight due to the smaller tree size. Also, the fruit on these trees can be more easily harvested. Figure 2 shows the relationship between tree size and picking rates. Hand harvesting rates in bushels per hour were significantly greater with the dwarf trees than with the taller standard varieties (Johnson, 1974). 


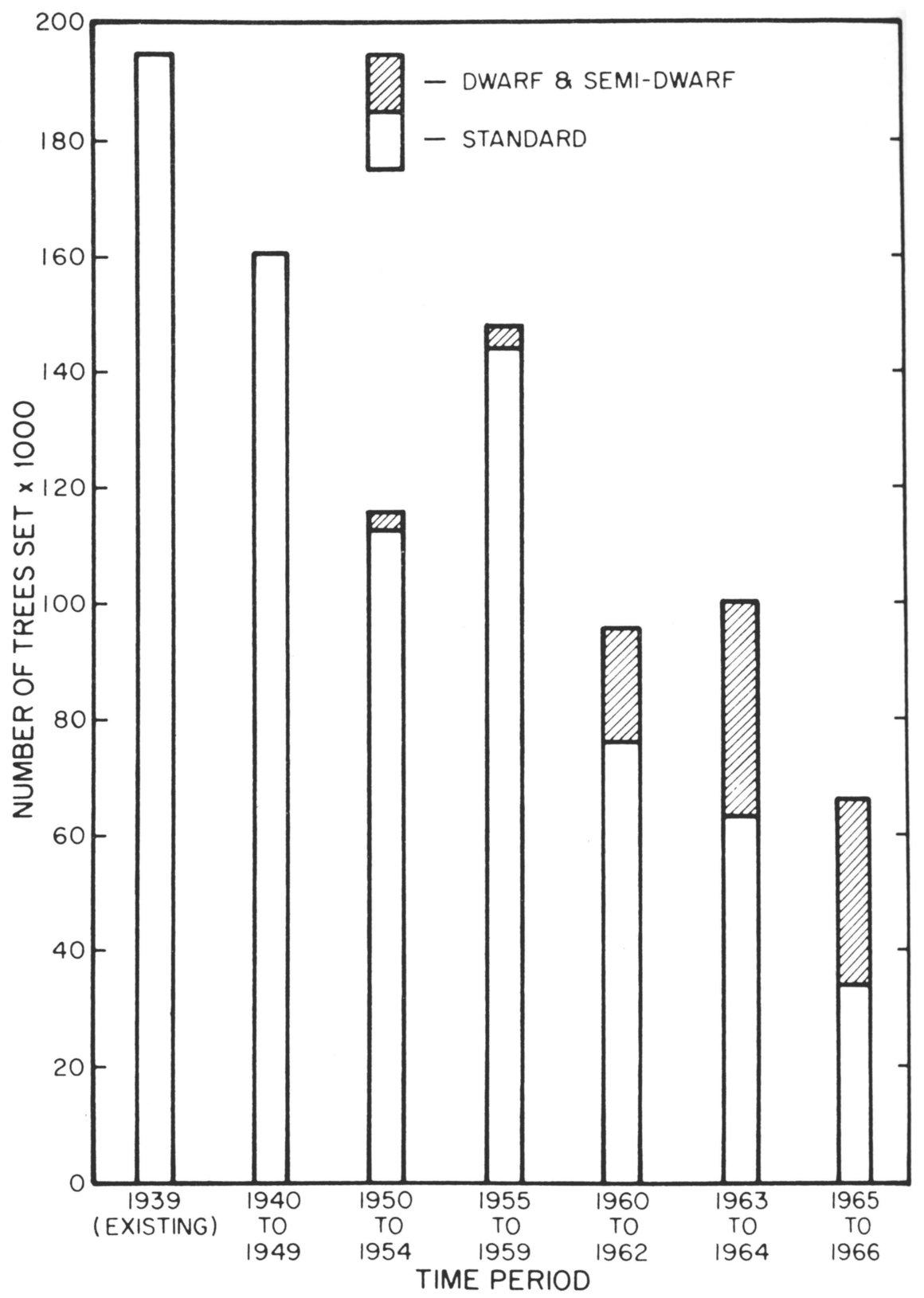

Figure 1. Number of Apple Trees in Commercial Orchards in West Virginia by Type and Year Set (Regional Summary of Fruit Tree Surveys, Selected Appalachian States, 1967). 


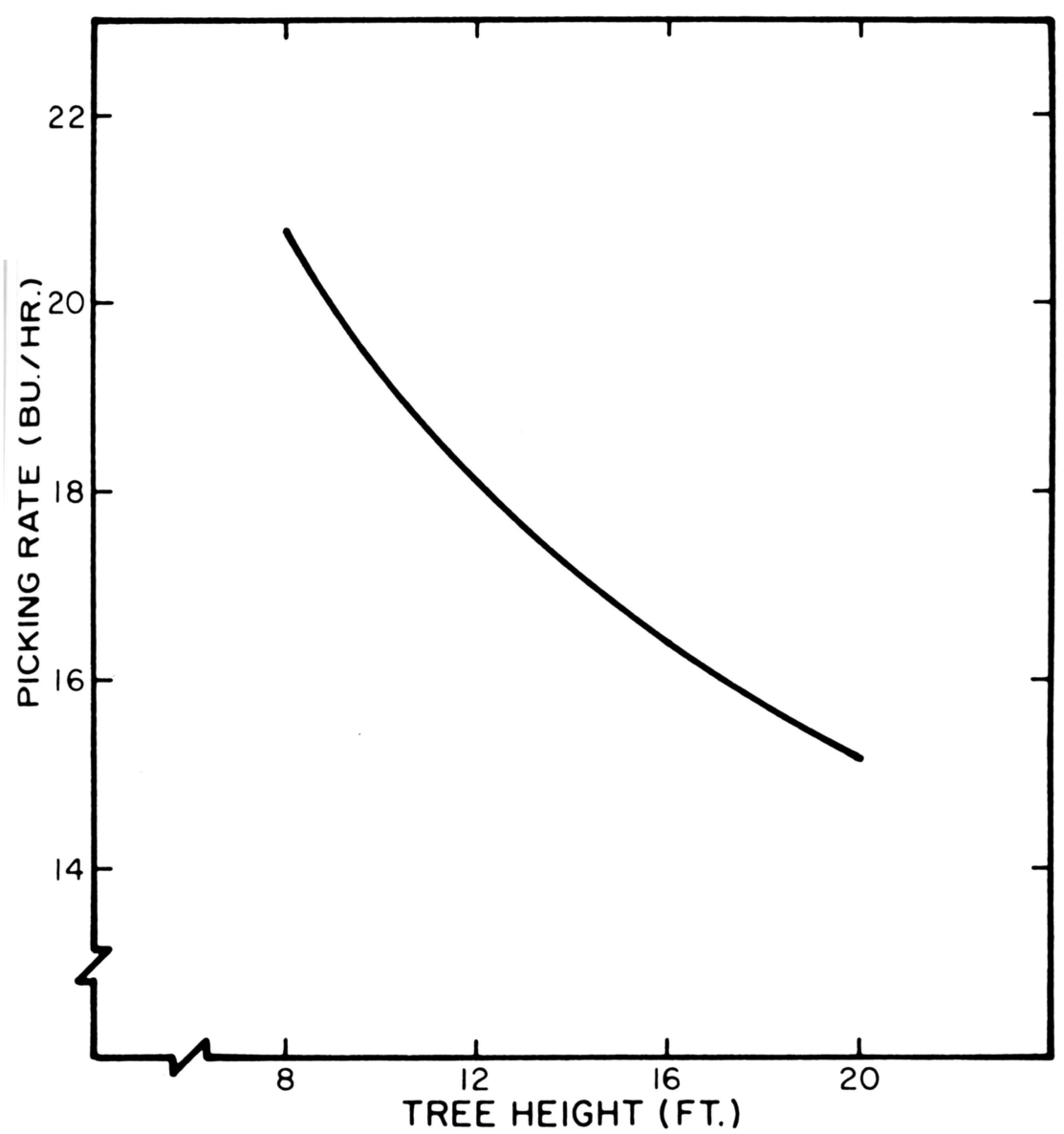

Figure 2. The Effect of Tree Size on Apple Picking Rates (J. M. Johnson, The Mountaineer Grower, 1974).

Another advantage of the dwarf apple trees is that they should be more suitable (with specialized shapes) for the introduction of mechanical harvesting. Increasing labor costs and labor shortages in many rural areas along with the need to harvest a large bulk in a relatively short time period are factors which are forecasting the widespread application of large-scale mechanical harvesting of apples in the future. 


\section{Establishment Costs}

There are an extremely large number of different production situations affecting the costs of establishing an apple orchard. For example, cost considerations would be different for establishing a semi-dwarf from a standard orchard than for establishing a new semi-dwarf orchard. Cost considerations would differ if the orchard was a specialized operation rather than part of a larger diversified farm. In general, however, it is more expensive to establish a dwarf apple orchard than a standard orchard. A study in the State of Washington in 1966 determined, based on establishing a 15-acre apple orchard on a 150-acre diversified farm, the accumulated three-year investment costs per acre of establishing apple trees on three different rootstocks (Doran and Hunter 1967). The cost per tree for the standard rootstock was $\$ 6.32$ (108 trees per acre). The cost per tree of the semi-dwarf was $\$ 4.12$ (based on 268 trees per acre), and the cost per tree of the full dwarf rootstock was $\$ 3.64$ (400 trees per acre).

Although these costs would vary over time and geographical regions, it can be seen that the dwarf trees are more expensive to establish. But it must be re-emphasized that these smaller, grafted trees produce more fruit per acre and they begin producing earlier than the standard rootstocks.

\section{Weaknesses Associated with Grafting}

In many cases the rootstock and scion fail to develop a complete union following grafting. This is called incompatibility; it results in poor performance of the tree such as weak trunks and limbs, insufficient yield, poorly anchored root systems, excessive breaking of unions, and tree mortality.

At this time it is not possible to predict the degree of compatibility in a stock-scion combination that has not been tried previously. The trial and error method must still be used to determine the compatibility of any new stock-scion combination because of the lack of other suitable testing methods.

\section{Methods for the Determination of Mechanical Properties of Wood}

Many techniques have been used to determine the mechanical properties of wood. Diener et al. (1969) in their analysis of graft unions in apple trees used free vibration of small fresh wood specimens as one means of early detection of incompatible unions in dwarf apple trees.

Other methods employ tension, torsion, or bending tests of wood specimens.

All of the above methods, however, are destructive, i.e. the wood has to be cut into pieces in order to obtain adequate specimens for the diverse tests.

Diener et al. (1966) stated that flexure testing is often preferable to torsion or tension testing when difficulty in gripping the specimen and measuring the resulting strains is encountered. Apple trees are included in this category. Flexure testing allows large, easily measured displacements without causing destruction or yield in the outer fibres of the specimen. 


\section{Nondestructive Testing of Live Wood}

Schroder et al. (1972) used a simple flexure test which could be applied to small trees while growing in the field. The apparatus used for this test was attached to a three-point linkage of a tractor. The bending jig was driven by a gear motor with a further reduced output in order to obtain the desired bending rate. The linear constant bending rate was approximately $10 \mathrm{in.} / \mathrm{min}$. In this test, a center load was applied to the trunk which was simply supported. The deflection and force were measured by an LVDT (Linear Variable Differential Transformer) and a load cell respectively and the output response was amplified and recorded.

Schroder also developed a theory for the analysis of the data obtained. He found that the storage modulus $\mathrm{E}_{11}$ and the loss tangent $\delta$ were significant nondestructive parameters for comparing stiffness and damping in grafted trees.

\section{OBJECTIVES OF THE STUDY}

There are several different rootstock-scion combinations presently being used on commercial orchards or being tested by various public and private agencies. The overall objective of this study is to determine which of the various combinations are most compatible and which are most effective in terms of fruit bearing capacity. In order to accomplish this objective, however, the mechanical properties of live apple wood had to be analyzed.

Thus, this study was initiated with the following specific objectives:

1. To redesign the appropriate test equipment for handling larger apple trees.

2. To determine the relationships between stiffness and alternative rootstock scion combinations.

3. To study the relationships between trunk and limb stiffness as a measure of fruit supporting capacity.

4. To determine the seasonal effects on trunk stiffness and limb stiffness.

\section{THEORETICAL ANALYSIS}

\section{Bending Equation for Elastic Tapered Beam with Uniaxial Modulus}

Schroder considered the tree trunks to be linearly tapered (Figure 3) having orthotropic viscoelastic properties.

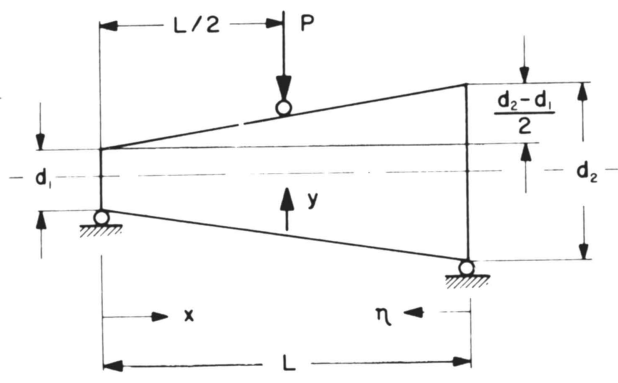

Figure 3. Uniformly Tapered Beam Used for Analysis of Simple Bending of Apple Trees. 
For the analysis the simplified Euler equation was used because deflections were small.

$$
E I(x) d^{2} y / d x^{2}=M
$$

where $\quad E=$ Young's Modulus

$I(x)=$ Moment of inertia of the cross section as a function of $x$

$\mathrm{M}=$ Bending moment

$y=$ Deflection

$x=$ Length along the beam

$\eta=$ Length along the beam (from right side)

The simply supported beam was considered to be of length $L$ and subject to the concentrated load P applied at the center of the beam as shown in Figure 3. Axial forces were neglected since this introduces an error of less than one percent as shown by Diener et al., 1966 and Diener et al., 1969.

The final deflection formula as developed by Schroder (1972) was

$$
y=8 \mathrm{PL}^{3} \mathrm{H} / \mathrm{E} \pi
$$

where

$$
H=2\left(U / D_{2}^{4}+V / d_{1}^{4}\right)-\left(A / d_{2}^{4}+Q / d_{1}^{4}\right)
$$

and

$$
\begin{aligned}
& \mathrm{U}=1 / 48+a / 48+a^{2} / 64+a^{3} / 96+5 a^{4} / 767+a^{5} / 256 \\
& \mathrm{~V}=1 / 48-\gamma / 48+\gamma^{2} / 64-\gamma^{3} / 96+5 \gamma^{4} / 767-\gamma^{5} / 256 \\
& \mathrm{~A}=1 / 8+a / 6+5 a^{2} / 32+a^{3} / 8+35 a^{4} / 384+a^{5} / 16 \\
& \mathrm{Q}=1 / 8=\gamma / 6+5 \gamma^{2} / 32-\gamma^{3} / 8+35 \gamma^{4} / 384-\gamma^{5} / 16 \\
& a=\left(\mathrm{d}_{2}-\mathrm{d}_{1}\right) / \mathrm{d}_{2} \\
& \gamma=\left(\mathrm{d}_{2}-\mathrm{d}_{1}\right) / \mathrm{d}_{1}
\end{aligned}
$$

Viscoelastic Model Solution. Figure 4 shows the linear standard solid rheological model used for the analysis of apple wood. Diener (1971) found that apple wood can be represented better by linear than by non-linear models.

The final bending equation for the viscoelastic tapered beam as developed by Schroder (1972) was

$$
y=8 P L{ }^{3} H /\left(E+\frac{E_{1} \tau}{t}\left(1-e^{-t / \tau}\right)\right) \pi
$$

solving equation (3) for $E+E_{1}$ and approximating $E+E_{1}$ by the storage modulus $E_{11}$ as shown by Diener et al., 1968, equation (4) was obtained

$$
\mathrm{E}_{11}=\frac{8 \mathrm{~L}^{3} \mathrm{H}}{\pi \mathrm{R}} \frac{\Delta \mathrm{P}}{\Delta \mathrm{t}}
$$


Figure 4. Standard Solid Three Parameter Rheological Model Used to Represent Live Apple Wood.

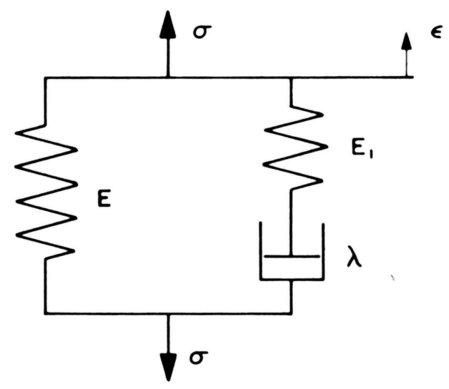

where $\Delta \mathrm{P} / \Delta \mathrm{t}$ represented the slope of the force vs. experimental time curve and $R$ is the loading velocity.

Loss Modulus - The Loss Modulus $\mathrm{E}_{22}$ may be approximated as shown by Diener et al., 1968 by

$$
E_{22}=\left(2 E_{11} / \pi\right)\left(1-E_{u} / E_{s}\right)
$$

where

$$
\begin{aligned}
E_{\mathrm{S}} & =\text { area under time-loading curve } \\
\mathrm{E}_{\mathrm{U}} & =\text { area under time-unloading curve } \\
\mathrm{E}_{11} & =\text { storage modulus }
\end{aligned}
$$

Loss Tangent. The loss tangent is defined as the ratio of the loss modulus and the storage modulus.

$$
\tan \delta=\frac{E_{22}}{E_{11}}
$$

\section{APPARATUS AND PROCEDURE}

\section{Test Plot}

The trees used for the experiment were purchased from a commercial nursery and planted at the West Virginia University Horticulture Farm during April 1970. The plot consisted of 10 replications each of Golden and Red Delicious on five different rootstocks: Seedling, EM VII, EM IX, EM 26, and MM 106. Red and Golden Delicious scions were used in this study since they account for more than one third of all apples produced in West Virginia (1969 West Virginia Agricultural Statistics).

The trees were planted on $6 \times 12$ foot spacings randomly in a plot consisting of 10 rows and 10 columns. The graft unions were situated two to five inches above the soil surface. The plot is bordered by a 10-15-year-old orchard on one side and by open field on the other three sides. 
The planting was cultivated and sprayed with the rest of the Horticulture orchard. Protection against mice and rabbits was provided by a one-quarter inch mesh fence.

\section{Redesigning of the Bending Apparatus}

The bending apparatus (Figure 5) constructed by Schroder was redesigned to obtain a lower bending rate. The drive mechanism (Figure 6) was driven by a Model FM-SP New England Gear motor with 20 R.P.M. output. This speed was further reduced by a specially designed screw-type transmission to obtain a linear constant bending rate of $1.25 \mathrm{in.} / \mathrm{min}$.

The bending jig applied a center load to the simply supported trunk. The supports consisted of two rollers with ball bearings for elimination of an axial load. The span was variable, but was set at 23.62 inches.

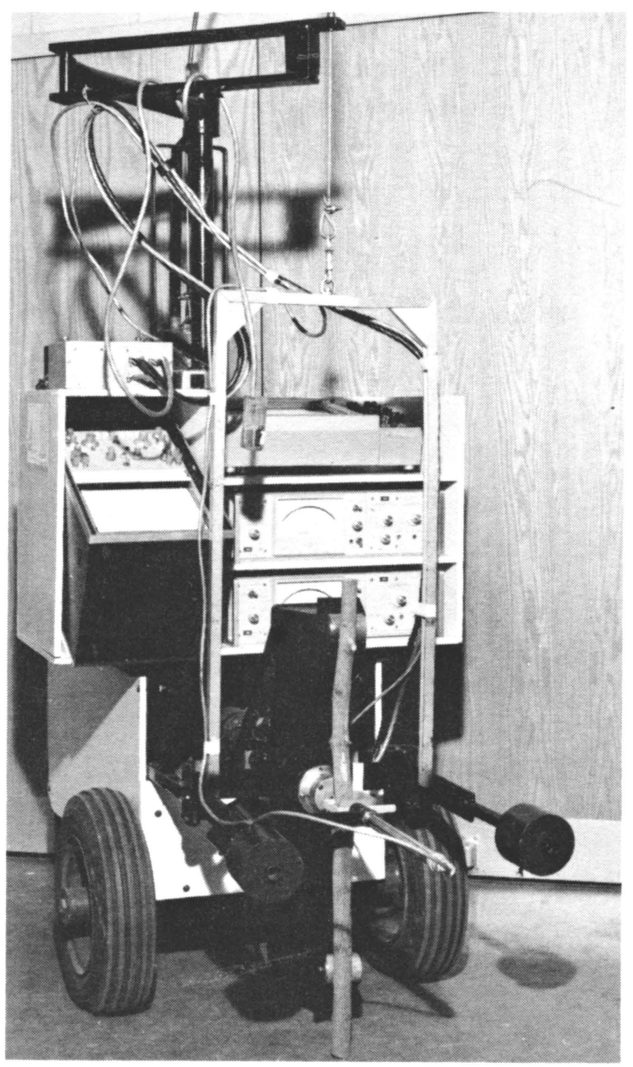

Figure 5. Bending Apparatus. 


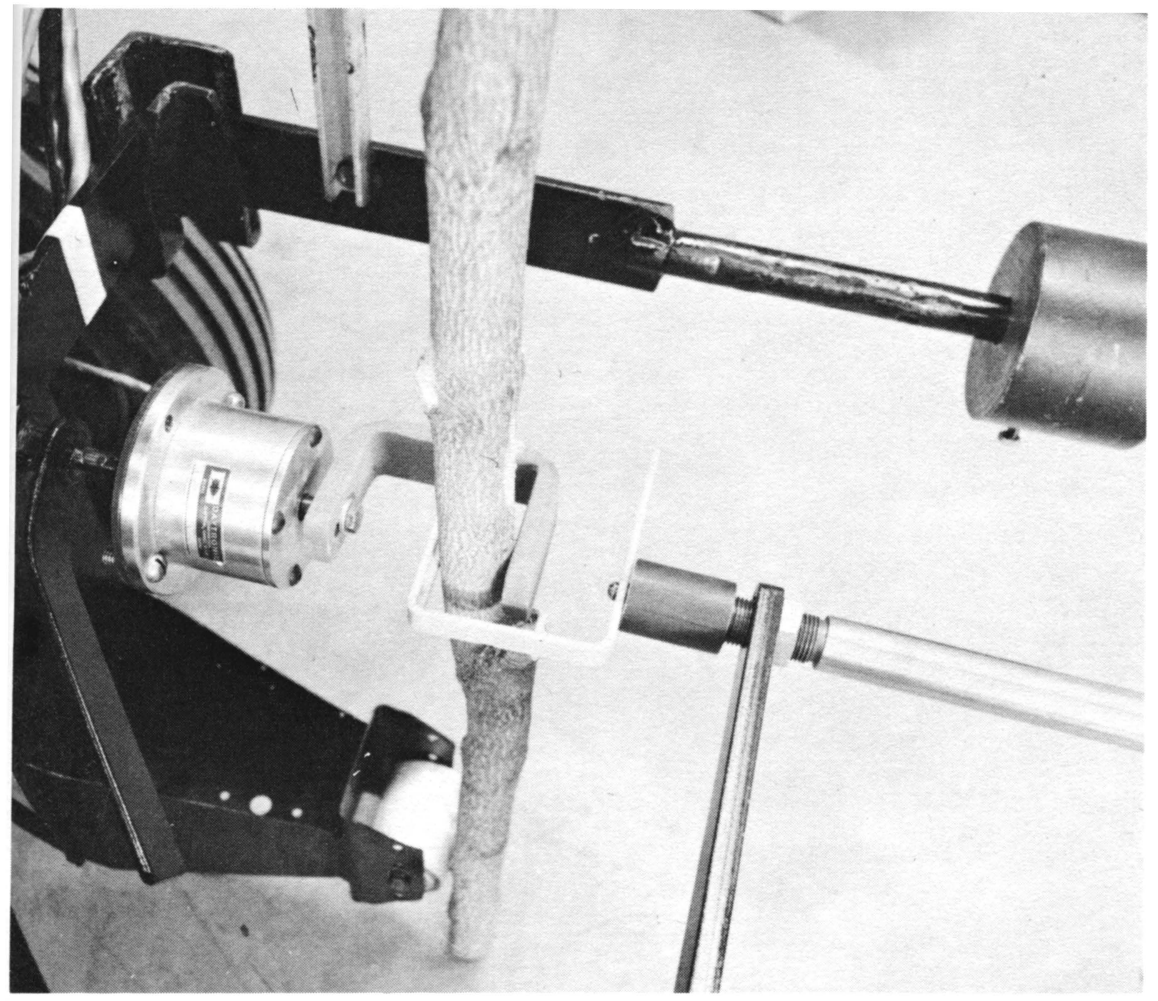

Figure 6. Close-up View of Bending Jig.

The bending force was applied to the trunk and measured by a load cell fastened to a hook, while the displacement was measured by an LVDT (Linear Variable Differential Transformer) fastened to a hook. This hook was clamped to the trunk in such a way as to follow the deflection of the trunk rather than the motion of the load cell.

The drive motor was controlled by an automatic control circuit for forward and reverse motion.

During the test in the field the complete bending apparatus was attached to the three-point linkage of a tractor (Figure 7). When actually performing a test the bending jib was hung on a cable having a counter weight for balance. Using this method the bending jig could easily be aligned with the trunk while bending and thus no external forces or moments were introduced.

The outputs of the load cell and the LVDT were amplified by two Daytronic amplifiers and recorded by a Mark 280 Brush strip chart recorder and a Moseley Model $135 \mathrm{X}$-Y recorder (Figure 8). 


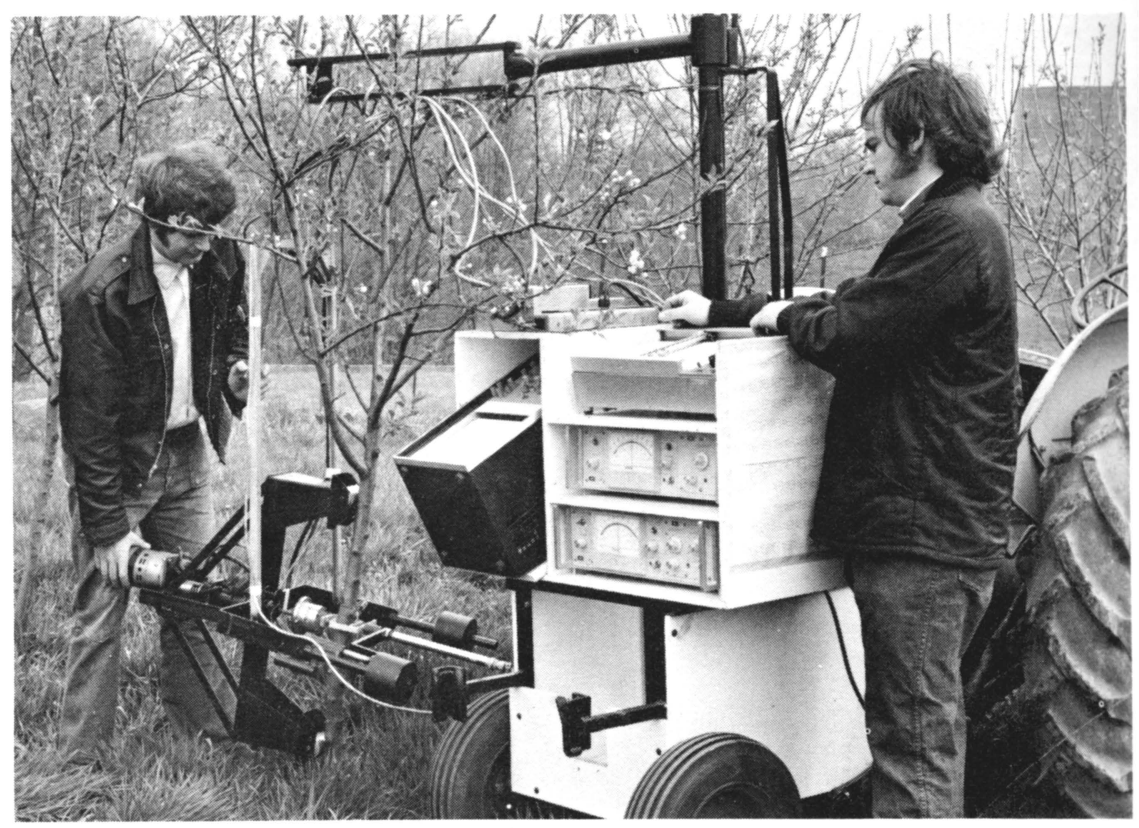

Figure 7. Bending Apparatus During Testing Procedure in Test Orchard.

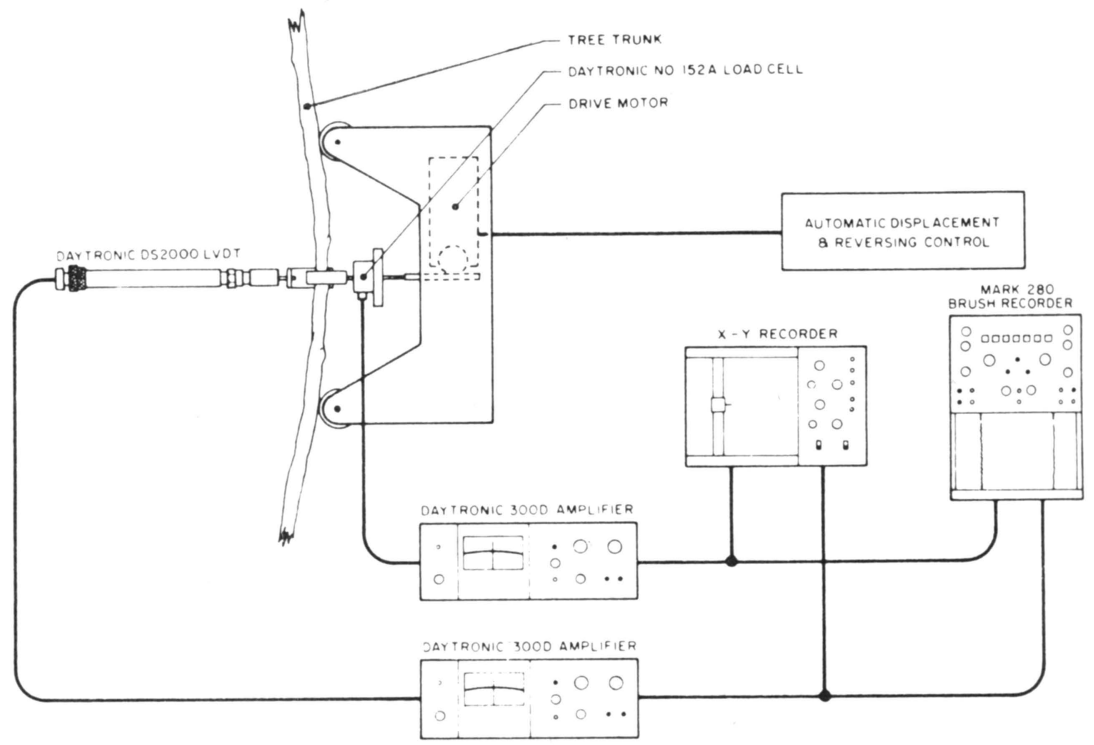

Figure 8. Block Diagram of Apple Tree Bending Apparatus. 


\section{Collection of Data}

Testing of Trees. All trees were tested while growing in the field. The bending test was performed above the graft union and the displacement was kept far below the yielding point of the tree. Displacement vs. time and force vs. time were recorded on the left and right channel of the Brush recorder respectively (Figure 9) while force vs. displacement values were recorded on the $X-Y$ recorder (Figure 10). The diameters of the trunks at the supporting points were recorded.
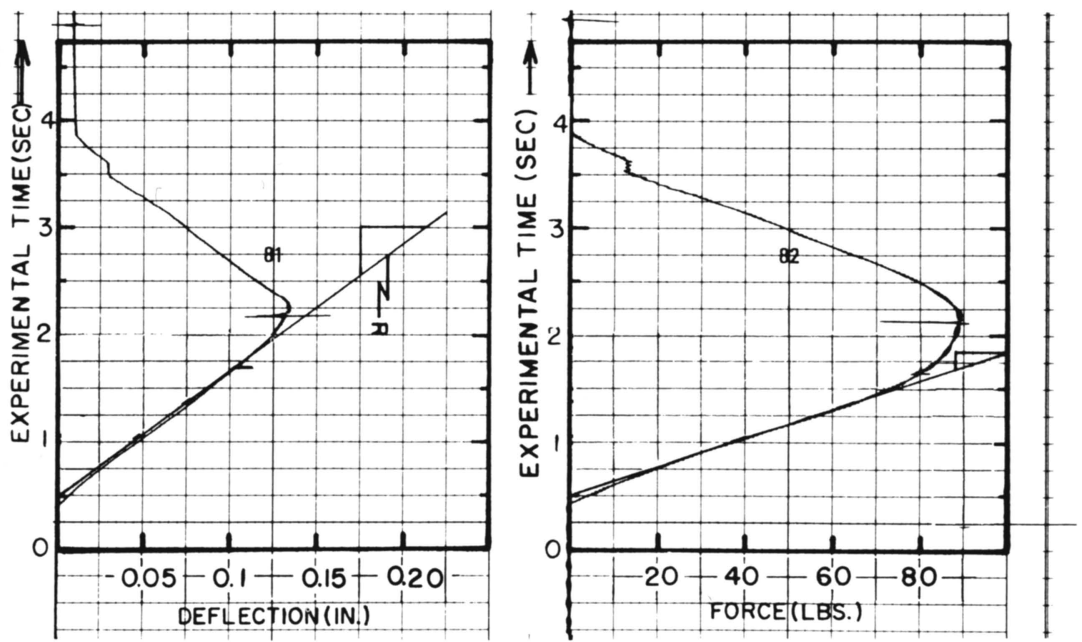

Figure 9. Loading and Unloading Curves for Live Apple Wood Showing Force and Displacement vs. Experimental Time.

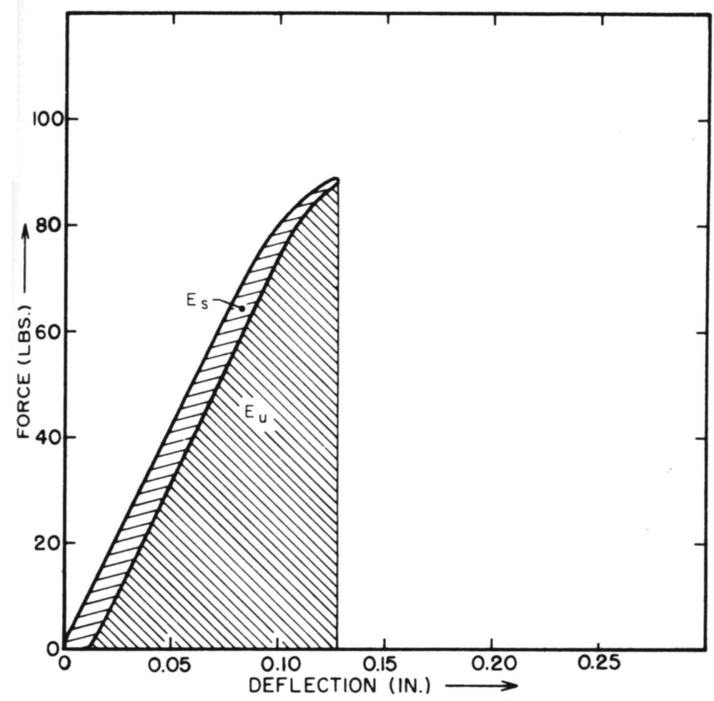

Figure 10. Loading and Unloading Curve for Live Apple Wood Showing Energy Stored Temporarily in the Wood. 
Testing of Limbs. Limbs with a diameter of approximately 0.3 inch were cut from each tree for a flexure test. These tests were performed on an Instron Universal Testing Instrument in the laboratory of the Agricultural Engineering Department (Figure 11). To keep the limbs from drying and changing their mechanical properties they were placed in water immediately after removal from the trees. When tested all leaves and twigs were removed from the limbs which were then placed on two supports of the instrument base, spanning a distance of eight inches. A center load was applied to the limbs by a load cell. The force output was amplified by a Daytronic Model $300 \mathrm{D}$ amplifier and recorded on a Moseley Model $135 \mathrm{X}$-Y recorder. Time was plotted on the $\mathrm{X}$-axis.

Measurement of Trunk Diameters. The simplest and most practical way to obtain the diameters was to measure the circumference at the supporting points by a metric tape in millimeters. From the circumference the diameters were easily calculated.

\section{RESULTS}

\section{Experimental Results}

Relationship of Storage Modulus and Loss Tangent. The storage modulus was inversely related to damping in trunks as shown in Figure 12. With increasing storage modulus, a decreasing loss tangent was observed. This was true for both Red and Golden Delicious varieties. This meant that there was low

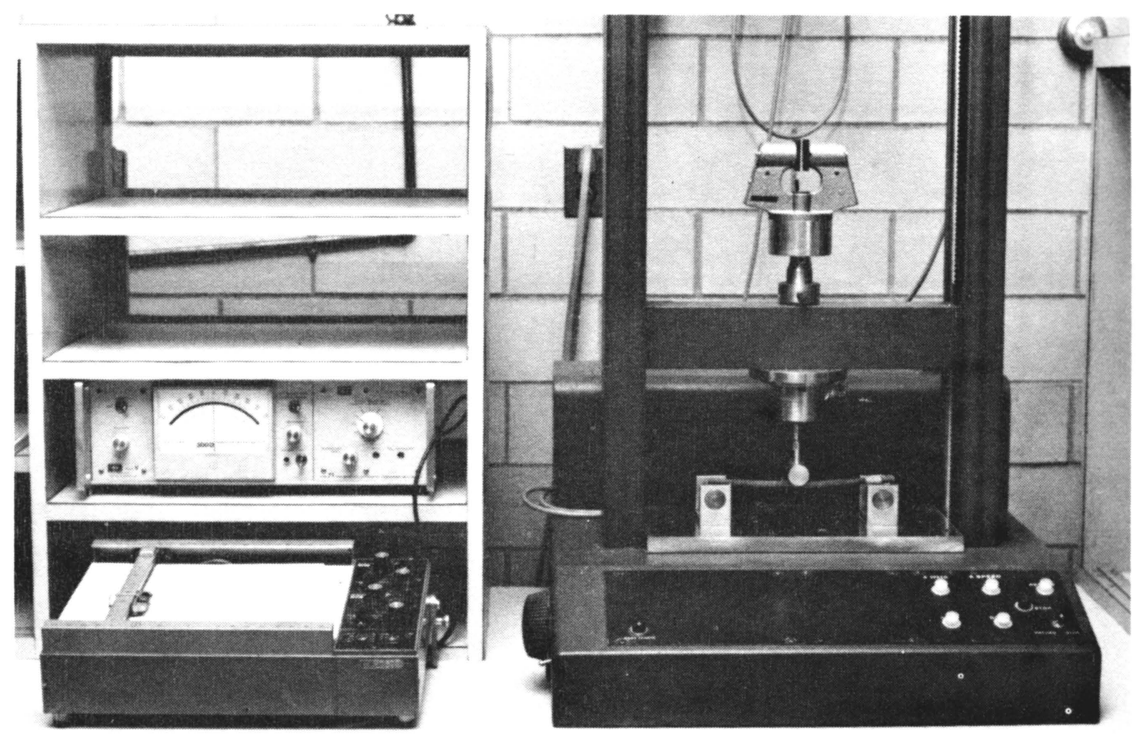

Figure 11. Instron Universal Testing Instrument with Set-Up for Simple Bending Test of Apple Limbs. 


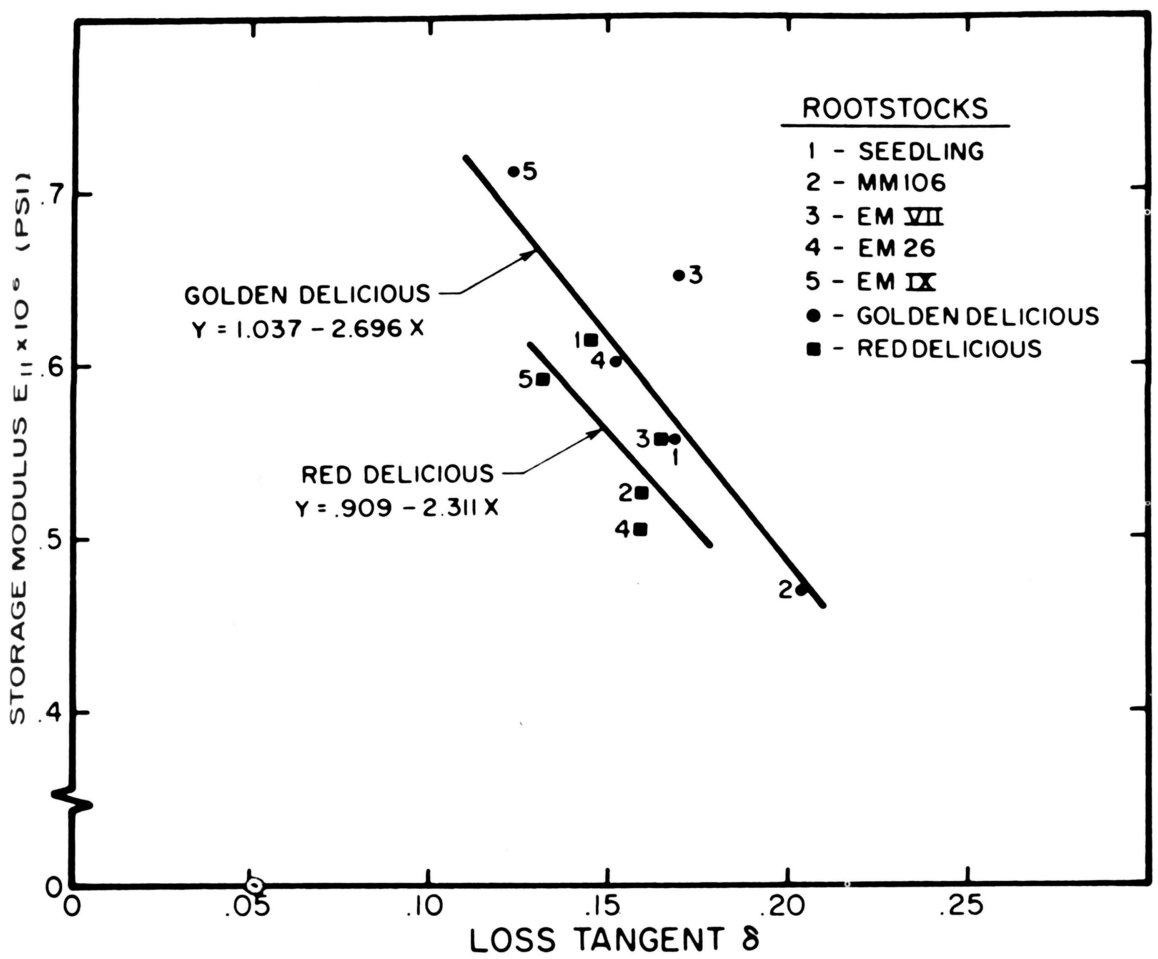

Figure 12. Relationship of Storage Modulus vs. Loss Tangent for Different Apple Variety and Rootstock Combinations.

damping present with high stiffness in the trunks. This is supported by the fact that there is more cellulose present in trunks with a high storage modulus causing the higher stiffness and there are more lignins present in trunks with a low storage modulus causing the higher damping.

Relationship of Trunk Stiffness vs. Limb Stiffness. As shown in Figure 13, there was almost no relationship between the trunk stiffness and the limb stiffness for Red Delicious. In the case of Golden Delicious the relationship was more distinct. Another interesting implication is that in Golden Delicious there appeared to be an increasing trunk stiffness associated with a decreasing limb stiffness.

Storage Modulus Means for Trunks. The comparison of the storage modulus means for trunks in Figure 14 shows a value of 685,000 psi for Golden Delicious as compared to 633,000 psi for Red Delicious. This represents a difference of only eight per cent. The various rootstocks show a significant variation in storage modulus. The range of the values is from 745,000 psi for EM IX to 575,000 psi for MM 106 (Table 1). 


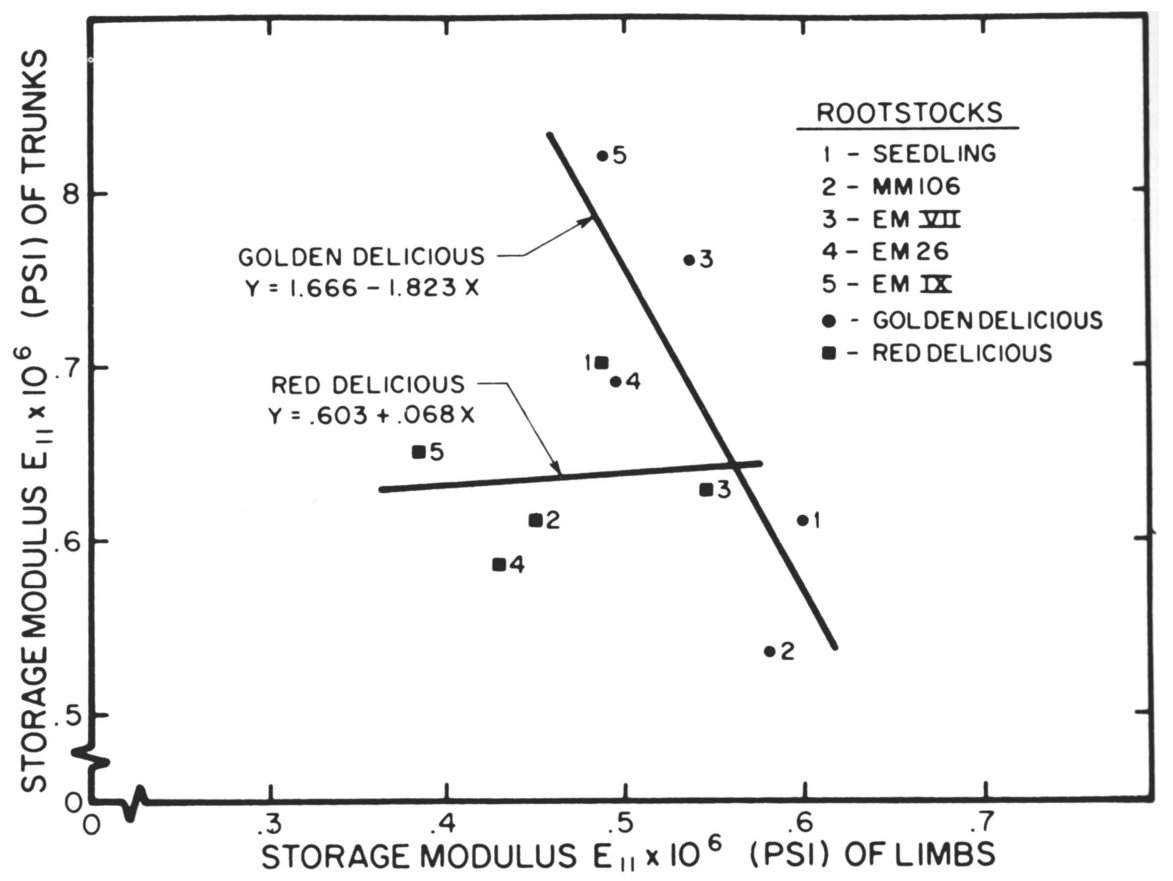

Figure 13. Relationship of Storage Modulus for Trunks vs. Storage Modulus for Limbs of Different Variety and Rootstock Combinations in Three-Year-Old Trees.

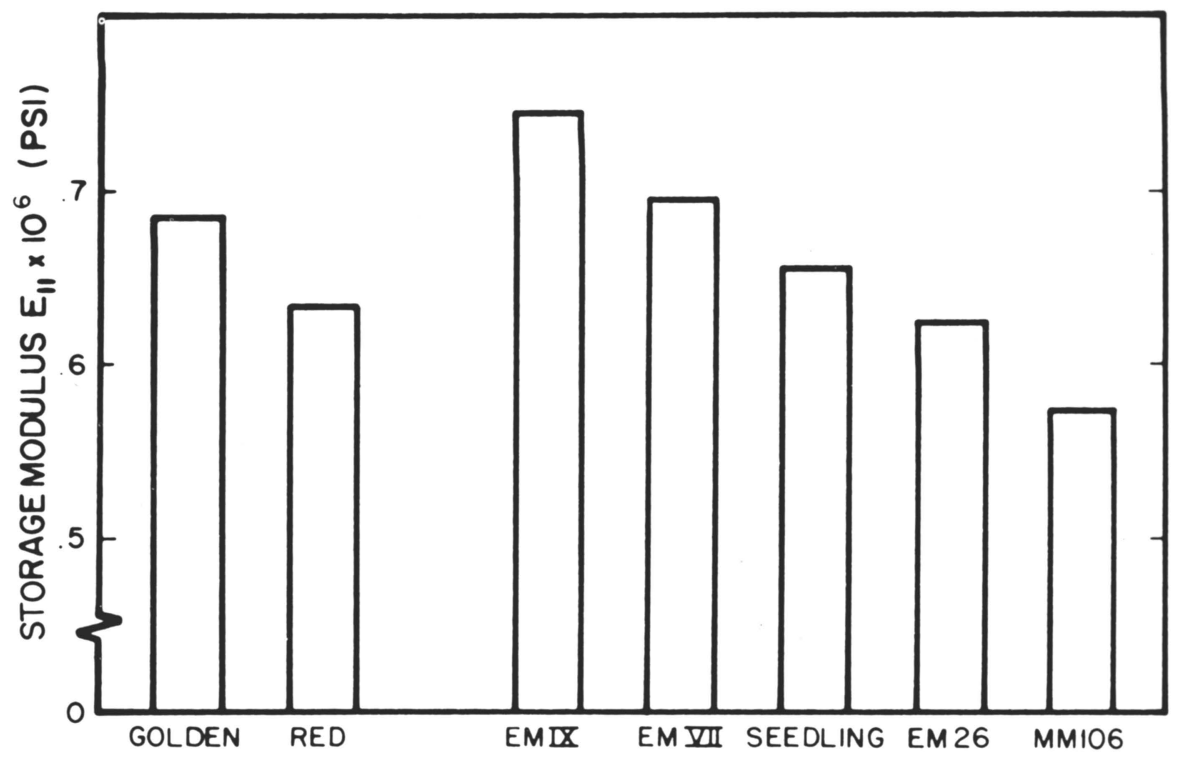

Figure 14. Comparison of Storage Modulus Means for Trunks of Varieties and Rootstocks in Three-Year-Old Trees. 


\section{TABLE 1}

\section{Analysis of Variance Table for Dependent Variable Trunk Stiffness (June-August-October)}

\begin{tabular}{lrrc}
\hline \hline Source & DF & F Value & Significance \\
\hline Scion & 1 & 1.829 & NS \\
Rootstock & 4 & 3.204 & $*$ \\
Scion x Rootstock & 4 & 2.070 & NS \\
Tree (Scion, Rootstock) & 80 & 2.651 & $* *$ \\
Season & 2 & 118.271 & NS \\
Scion $\times$ Season & 2 & 0.527 & $* *$ \\
Root x Season & 8 & 2.893 & $*$ \\
Scion x Root x Season & 8 & 2.065 & \\
\hline
\end{tabular}

\footnotetext{
* Significance at $a=0.05$ level

** Significance at $a=0.01$ level NS-Not significant
}

Storage Modulus Means for Limbs. Storage Modulus means of the limbs as shown in Figure 15 were in part opposite to those of the trunks. EM IX produced the lowest stiffness of $442,000 \mathrm{psi}$ as compared to the highest value of 540,000 psi for EM VII (Table 2).

Effect of Rootstocks on Storage Modulus in Trunks. Figure 16 shows some interaction effect of variety in the case of Red Delicious on Seedling and MM 106 rootstocks, otherwise the same pattern is present as shown in Figure 14. Rootstocks had a significant effect on trunk storage modulus (Table 1).

Effect of Rootstocks on Storage Modulus in Limbs. Figure 16 also shows a variety interaction for the case of Red Delicious on EM VII. Otherwise the curves follow similar patterns to that shown in Figure 15 . The effect of rootstock is highly significant on limb stiffness (Table 2).

Effect of Seasons on Storage Modulus in Trunks and Limbs. There is a distinct seasonal effect on stiffness of all trunks as well as on the stiffness of all limbs (Figure 17). In trunks the value of the storage modulus was lowest in June. In August the value increased by approximately 31 per cent for both Golden and Red Delicious. Until harvest time in October the values increased again by 16 per cent compared to August (Table 1).

On limbs, however, the season had the opposite effect. While there were no data taken in June, the values for October show a decrease of approximately 10 per cent as compared to the August values in Red and Golden Delicious. 


\section{TABLE 2}

\section{Effects of Source Factors on Limb Stiffness in October}

\begin{tabular}{lccc} 
Source & DF & F Value & Significance \\
\hline Trunk Stiffness & 1 & 0.900 & NS \\
Scion & 1 & 9.393 & $* *$ \\
Root & 4 & 4.855 & $* *$ \\
Scion x Rootstock & 4 & 2.510 & $*$ \\
\hline
\end{tabular}

* Significance at $a=0.05$ level

** Significance at $a=0.01$ level NS-Not significant

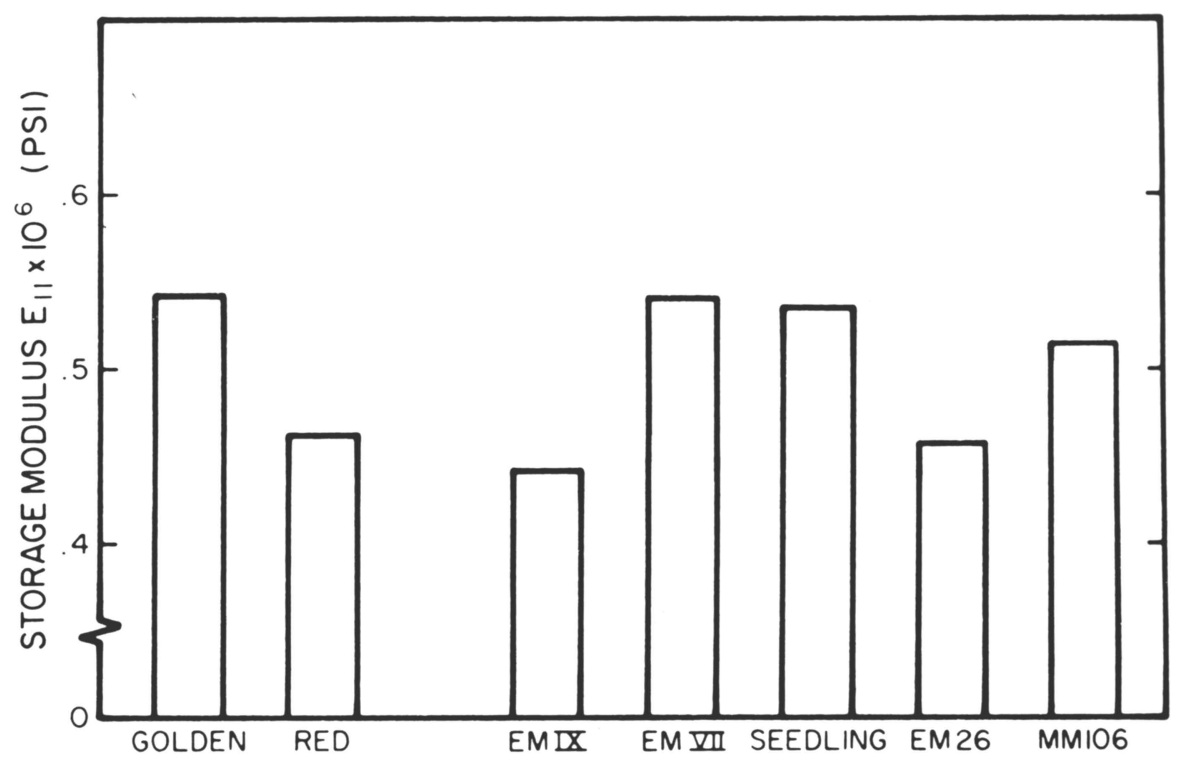

Figure 15. Comparison of Storage Modulus Means for Limbs of Varieties and Rootstocks in Three-Year-Old Trees.

\section{Statistical Analysis of Experimental Data}

The sources of variation tested were scions, rootstocks, interaction of scions and rootstocks, and seasons and interaction of seasons with the above sources of variation. Trunk stiffness and damping were included as covariates. The experiment tested the effect of the sources of variation on the means of trunk stiffness, limb stiffness, and trunk damping. It further tested the effect of trunk stiffness on limb stiffness and the effect of damping on trunk stiffness. 


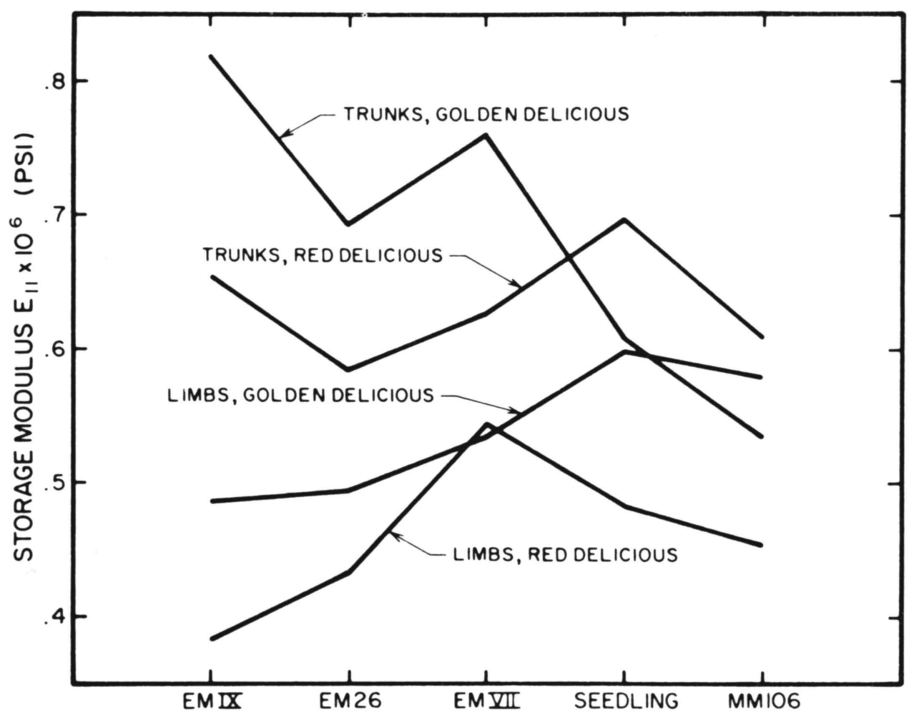

Figure 16. Effect of Rootstocks on Storage Modulus in Trunks and Limbs of Different Varieties in Three-Year-Old Trees.

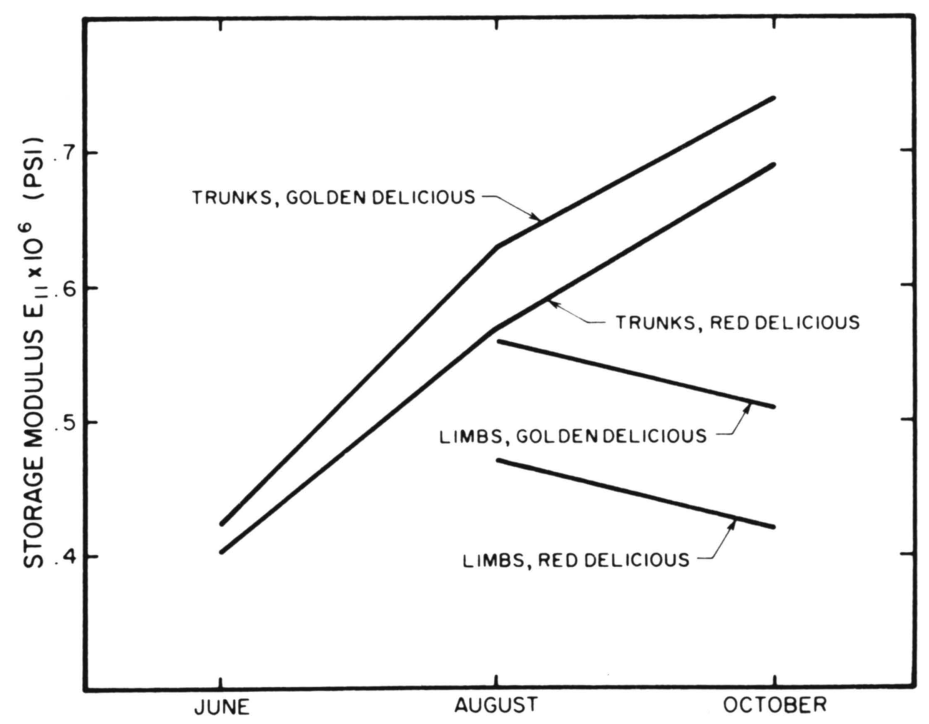

Figure 17. Seasonal Effects on Storage Modulus in Trunks and Limbs in ThreeYear-Old Trees. 
Statistical Analysis System Results. Tables 1 and 2 show the significant factors obtained from the Analysis of Variance Tables as a result of the Statistical Analysis System for the test performed in October. One star $\left({ }^{*}\right)$ denotes significance at $a=0.05$ while two stars $\left({ }^{* *}\right)$ denote significance at $a=$ 0.01 .

Significance implies the rejection of the null hypothesis while nonsignificance suggests the acceptance of the null hypothesis that there is no effect of the sources of variability on the dependent variables.

\section{CONCLUSIONS}

1. The storage modulus mean for Golden Delicious trunks was 685,000 psi and 633,000 psi in Red Delicious trunks.

2. The storage modulus mean for Golden Delicious limbs was 542,000 psi and 461,000 psi in Red Delicious limbs.

3. Rootstocks had a significant effect on storage modulus of trunks of grafted trees as shown by the following values where

$$
\begin{aligned}
& \text { EM IX }-747,000 \mathrm{psi} \\
& \text { EM VII }-697,000 \mathrm{psi} \\
& \text { Seedling }-656,000 \mathrm{psi} \\
& \text { EM } 26-627,000 \mathrm{psi} \\
& \text { MM } 106-575,000 \mathrm{psi}
\end{aligned}
$$

4. The limb storage modulus was influenced highly significantly by different rootstocks and did not conform to the trunk stiffness trends. For the various rootstocks the following values of the storage modulus in limbs were obtained:

$$
\begin{aligned}
& \text { EM IX }-442,000 \text { psi } \\
& \text { EM VII }-540,000 \text { psi } \\
& \text { Seedling }-535,000 \text { psi } \\
& \text { EM } 26-460,000 \text { psi } \\
& \text { MM } 106-513,000 \text { psi }
\end{aligned}
$$

5. There appears to be an inverse relationship between damping and trunk stiffness in the grafted trees tested. Trunks having high stiffness have low damping values and those having low stiffness had high damping values (Figure 10), but statistical support for this is lacking.

6. On the average the storage modulus was higher in Golden Delicious trunks than in Red Delicious trunks. However, Seedling and MM 106 produced higher storage modulus values in Red Delicious than in Golden Delicious trunks.

7. On the average the storage modulus was higher in Golden Delicious limbs than in Red Delicious limbs. However, EM VII produced a higher storage modulus value in Red Delicious than in Golden Delicious limbs. 
8. There was a highly significant seasonal effect on trunk stiffness. In trunks the storage modulus means increased from 415,000 psi in June to 715,000 psi in October.

9. There was also a strong seasonal effect on limb stiffness, but the trend was opposite to the trunks. From August to October the average storage modulus decreased from 515,000 psi to 465,000 psi in limbs.

10. Flexure testing is an effective nondestructive method for detecting differences in the mechanical properties of young grafted apple trees.

11. From the data obtained it can be concluded that EM VII and EM 26 are preferable dwarfing rootstocks. EM IX appears to be too stiff and thus too brittle. MM 106 is susceptable to Phytophthora cacporum, a fungus that kills the tree, and it produced the lowest stiffness of all trunks tested.

12. At this stage of the study, rootstock EM VII can be recommended for use because it produced trunks and limbs of suitable stiffness.

13. For the first time it has been shown that rootstocks can alter the physical properties of scion wood produced on them. 


\section{LITERATURE CITED}

Anonymous

1967

\section{Anonymous}

1969

Anonymous

1972

1967 Regional Summary of Fruit Tree Surveys, Selected Appalachian States, USDA Statistical Reporting Service, Crop Reporting Bulletin, Washington, D.C.

1969 West Virginia Agricultural Statistics, W. Va. Crop Reporting Service, W. V. Department of Agriculture, C. R. Bull. No. 8, Charleston, WV.

1972 Agricultural Statistics, S. R. S., U. S. D. A., Washington, D. C., U. S. Government Printing Office.

Barr, A. J. and J. H. Goodnight

1972

Statistical Analysis System. North Carolina State University, North Carolina.

Diener, R. G., W. A. Bradley and G. E. Mase

1966 A Deflection Algorithm and Viscoelastic Model for Determining Relaxation Modulus from a Simple Bending Test. Michigan Agricultural Experiment Station Quarterly Bull. 49(4): 28-42.

Diener, R. G., F. H. Buelow and G. D. Mase

1968 Viscoelastic Analysis of the Behavior and Properties of Cherry Bark and Wood Under Static and Dynamic Loading. Trans. ASAE 2(3):323-331.

Diener, R. G., J. H. Levin and W. A. Bradley

1969 Seasonal Changes in Creep, Relaxation and Damping in Apple Tree Limbs - Factors Which Effect Mechanical Harvesting. Trans. ASAE 12(2): 137-140.

Diener, R. G. and E. C. Dubbe

1971

Use of a Three Parameter Rheological Model for Measuring Properties of Wood in Grafted Apple Trees. Trans. ASAE 14(3):420-427.

Doran, S. M. and R. E. Hunter 1967

The Cost of Establishing an Apple Orchard on Standard, Semi-Dwarf and Full Dwarfing Rootstock in the Columbia Basin, Washington, Cooperative Extension Service, College of Agriculture, Washington State University, Pullman, Washington.

Johnson, J.M. 1974

The Mountaineer Grower, Proceedings, Section 3, No. 335.

Koenig, H. W. 1961

Ermittlung der Verformungen von geraden Staeben mit linear veraenderlichen Querschnittsabmessungen. VDI-Z $103 \mathrm{Nr}$. 35:11.

Little, T. M. and F. J. Hills

1966 Experimental Methods for Extension Workers. University of California, Agricultural Extension Service.

Schroder, W. G. 1972

Mechanical Properties of Bud Grafts in Fruit Trees. Unpublished M.S. Thesis, West Virginia University, Morgantown, West Virginia

Snedecor, G. W. and W. G. Cochran

1972 Statistical Methods. The lowa State University Press, Ames, lowa.

Suggs, C. W. and W. E. Splinter

1965 Mechanical Properties of Tobacco Stalks, Trans. ASAE 8(3):361-364. 